\title{
How important is genetic engineering to European seed firms?
}

\section{Anthony Arundel, Matthias Hocke, and Joyce Tait}

The rapid adoption of genetic engineering by multinational seed firms has led some observers to conclude that genetic engineering is now the dominant technology for developing new seed varieties. If true, genetic engineering must offer firms economic advantages over alternative methods of developing seed varieties. A recent European survey provides some data on the actual use of genetic engineering as well as on the relationship between the type of seed development technology in use and several economic outcomes ${ }^{2}$.

The survey was conducted in May and June of 1999, just before the European Union announced a moratorium on GM crops. All seed firms were surveyed in Germany, the UK, France, the Netherlands, Spain, and Denmark. These countries are the home base for most of the EU's seed firms. The survey response rate was $72 \%$. The results given here are limited to 99 respondent firms with seed development programs.

The survey obtained an estimate of the distribution of each firm's development budget allotted in 1999 to three methods for producing new seeds and the expected distribution in 2002. The three technologies are genetic engineering, conventional plant breeding, and assisted conventional breeding, in which conventional techniques are supported by gene markers and gene sequencing. The firms are classified into three groups, based on the most advanced technology in use. In 1999, 33\% of the firms used some genetic engineering, 23\% used some assisted conventional breeding (but not genetic engineering), and $44 \%$ only used conventional plant breeding technology. In $2002,49 \%$ of the firms expect to use genetic engineering, whereas only $20 \%$ will be limited to conventional plant breeding.

Not surprisingly, larger firms are more likely to use advanced plant breeding tech-

Anthony Arundel is senior researcher and Matthias Hocke is research fellow at the Maastricht Economic Research Institute on Innovation and Technology (MERIT), University of Maastricht, The Netherlands (A.arundel@merit.unimaas.nl; m.hocke@merit.unimaas.nl). Joyce Tait is director, SUPRA (Scottish Universities Policy Research and Advice Network), University of Edinburgh,UK (joyce.tait@ed.ac.uk). nologies. Firms that used genetic engineering in 1999 accounted for $68 \%$ of total employment among the 99 firms. In 2002, firms that can use genetic engineering will account for almost $80 \%$ of employment.

Although most employment is among seed firms that can use genetic engineering, some firms might only use this technology for a few elite seed varieties. A key question is what percentage of the total research budget among these firms is allotted to each method for developing new seeds. The answer gives a measure of the importance of genetic engineering.

Only $10 \%$ of the total crop development budget, summed across all 99 respondent firms, was spent on genetic engineering in 1999 , compared to $17 \%$ for assisted conventional breeding and $73 \%$ for conventional breeding. However, this is not necessarily a reflection of the actual role of genetic engineering in developing new seeds, since some of the expenditures on conventional plant breeding could be used to test GM varieties.

A maximum estimate of the importance of genetic engineering can be obtained by assuming that only genetic engineering and assisted conventional techniques are used to develop new seed varieties. On this basis, $38 \%$ of the 1999 budget for developing new seeds would have used genetic engineering. This share is expected to decline slightly to $36 \%$ in 2002.

There were few differences in economic outcomes by the most advanced technology in use. The number of employees in developmental tasks such as R\&D and field testing was expected to increase slightly faster among firms that only used conventional plant breeding in 1999, but employment growth rates did not vary by whether or not these firms planned to adopt genetic engineering, assisted conventional breeding, or neither. There was also no difference in average seed sales per employee by the type of technology in use. The only significant difference was for exports to non-EU countries. Firms whose most advanced technology was assisted conventional breeding exported $37 \%$ of their output, compared with $20 \%$ for firms using genetic engineering. This difference is partly explained by the fact that multinational firms, which are the most likely to use genetic engineering, can serve export markets from their foreign subsidiaries.
Thus, in contradiction to various popularizations, genetic engineering is not yet the "dominant" seed development technology in Europe. On reflection, this should not be surprising, since $74 \%$ of all GM field trials in Europe in the 1990s were for only three crops: corn, sugar beet, and oilseeds. Nor is there any evidence from this study to show that genetic engineering confers economic advantages over alternative technologies, although it is probably too early for such advantages to show up.

Of course, the use of genetic engineering in Europe, and its economic benefits, could be reduced by public opposition to GM foods and uncertain regulatory conditions. Nevertheless, interviews carried out in 1999 as part of this research (see ref. 2) with the 12 largest European seed firms showed that they remain committed to the use of genetic engineering. They also believe that "second wave" GM crops that provide effective disease resistance or beneficial output traits will be better received by the European public.

The results suggest that European seed firms are hedging their bets so that they can succeed in either a favorable or hostile environment toward GM crops. On the one hand, their exposure to the effects of unfavorable markets for GM crops is limited, since only a minority of their total spending to develop new seeds is based on genetic engineering. On the other hand, by 2002, $80 \%$ of employment will be in firms with the ability to use genetic engineering, whereas another $14 \%$ of employment will be among firms that can use marker technology and gene sequencing ${ }^{2}$.

Although it is premature to state that genetic engineering is now the dominant technology for developing new seed varieties, the ability to use genetic engineering, given suitable economic and regulatory conditions, is rapidly extending to the entire European seed sector. It would be extremely useful to have similar data for the United States and Canada in order to carry out a comprehensive and reality-based assessment of the present and future role of genetic technologies in the development of new crop varieties.

\footnotetext{
1. Buttel, F. Agricultural biotechnology: its recent evolution and implications for agrofood political economy. Sociological Research Online 4, no. 3 (1999).

2. The research was funded by the European Commission under "Policy Influences on Technology for Agriculture," TSER project No. PL97/1280. The full report can be obtained from the authors.
} 